Thorax (1972), 27, 463.

\title{
Experience with mediastinoscopy
}

\author{
T. L. OTTO ${ }^{1}$, J. ZASŁONKA and M. ŁUKIAŃSKI
}

Institute of Tuberculosis and Chest Diseases, Warsaw, Second Surgical Department, Medical Academy. Eódź, and Department of Thoracic Surgery, Institute of Postgraduate Studies, Zakopane, Poland

Six hundred and eighty diagnostic mediastinoscopies are presented. Of these, 552 were classical, 114 anterior mediastinal, 12 posterior mediastinal, and 2 from below the sternum. In addition, 20 therapeutic mediastinoscopies were performed for the insertion of a pacemaker electrode or evacuation of a mediastinal cyst.

Of 125 mediastinoscopies performed on patients with an initial diagnosis of sarcoidosis, in most the diagnosis was confirmed, the rate of false negative results being $2 \cdot 4 \%$.

Extremely encouraging were the results in patients with an initial diagnosis of Hodgkin's disease. Out of 60 patients, a different diagnosis was established in 30 and further follow-up proved this to be correct. In mediastinal tumours the results were discouraging, the rate of false results being as high as $43 \%$.

Four hundred and ten patients were mediastinoscoped for lung cancer. In 52, mediastinoscopy was the first successful biopsy. Metastases to lymph nodes were found in 139 (33.9\%). The percentage of exploratory thoracotomies following the introduction of mediastinoscopy fell from $22 \%$ to $14 \%$.

Mediastinoscopy was also used to investigate the spread of oesophageal cancer and enabled us to exclude patients who were obviously inoperable.

Mediastinal and pulmonary diseases involving the lymphatic system often present considerable diagnostic difficulties. In such cases the diagnosis has to be based on direct biopsy of the involved and enlarged lymph nodes. In pulmonary sarcoidosis, Hodgkin's disease, and, less frequently, in tuberculosis, biopsy permits a correct diagnosis and the institution of adequate treatment. In case of malignant growths, especially in pulmonary cancer, such a biopsy can reveal the extent of the lesion and thus determine the operability of the tumour.

The first attempts at mediastinoscopy were those of Jehn and Nissen in 1927 and Harken in 1954, but they did not explore below the level of the aortic arch (Zenker, 1965). It was Carlens in 1959 who introduced mediastinoscopy as it is performed today and who designed the equipment for its performance. In his orginal description, mediastinoscopy allowed the approach to paratracheal, subcarinal, and hilar nodes by dissection of an artificial channel in loose tissues of the mediastinum, in front of the trachea, and alongside the main bronchi. Specht (1965) developed this method further and applied it to inspection of the anterior and posterior mediastinum ; thus it became possible to evaluate the spread of carcinoma of the oeso-

1Reprint requests: T.J.O., ul. Ptocka 26, Warsaw. phagus and to take biopsies of mediastinal tumours. Carlens himself tried to introduce mediastinoscopy for therapeutic as well as diagnostic purposes, by applying it to the insertion of atrial-triggered pacemaker electrodes and to resection of the thymus (Carlens, Johansson, Karlöf, and Lagergren, 1965; Carlens, Johansson, and Olsson, 1967). However, the development of more sophisticated pacemakers limited the former method whereas the latter never became generally accepted.

The use of mediastinoscopy in therapy is only occasional. As a diagnostic method it is highly successful and has been adopted in many countries. The results obtained in many centres are uniformly good ; however, selection of patients is quite often limited to certain ailments. We here present summarized material from three centres. Mediastinoscopy was introduced in these centres in 1964-65 and this summary includes cases diagnosed up to the end of 1970.

\section{MATERIAL AND METHODS}

Six hundred and eighty diagnostic and 20 therapeutic mediastinoscopies were carried out. Of the 680 diagnostic mediastinoscopies 552 were 'classical', according to Carlens, 114 anterior mediastinal after Specht, 12 posterior mediastinal after Specht, and 2 anterior mediastinal through a xiphoid approach (Fig. 1). 


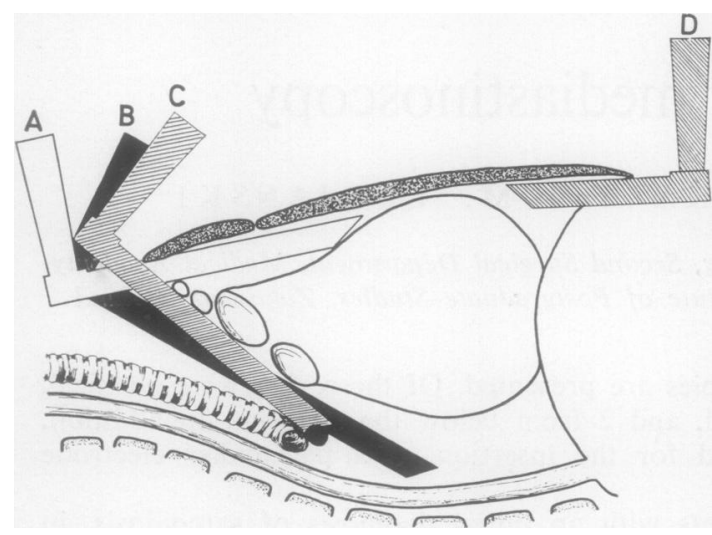

FIG. 1. Various forms of mediastinoscopy: $(A)$ anterior mediastinoscopy by Specht; $(B)$ posterior mediastinoscopy by Specht; (C) classical mediastinoscopy, as introduced by Carlens; (D) mediastinoscopy by way of the xiphoid approach.

Out of 20 therapeutic mediastinoscopies 12 were performed for the insertion of pacemaker electrodes. In these cases the mediastinum was approached in the usual manner and the atrial-triggered electrode was advanced alongside the trachea, past the tracheal bifurcation, and then placed as close to the left atrium as possible so that $\mathbf{P}$-wave voltage for triggering purposes was at least $2-3 \mathrm{mV}$. For insertion of an electrode in the proper position, a longer model of mediastinoscope was used. The electrodes were left without fixation; nevertheless they had no tendency to dislocate even during coughing or exercise. This method, together with transvenous implantation of a pacing electrode, rendered thoracotomy unnecessary and allowed satisfactory pacing (Stopczyk et al., 1968). In two instances it was possible to remove through the mediastinoscope a mediastinal cyst. Before removal, the cyst was partially dissected, then its contents were aspirated, and dissection was completed. After removal the cyst was filled with fluid which confirmed that the removal was complete. Other therapeutic mediastinoscopies were usually restricted to aspiration of pus or fluid.

In diagnostic mediastinoscopies an attempt was always made to take a biopsy of those nodes which on radiography seemed most enlarged, and, if possible, from more than one place. Naturally such a policy was always observed when the spread of lung cancer or oesophageal cancer was being investigated.

\section{RESULTS AND DISCUSSION}

The results of mediastinoscopy in various pulmonary and mediastinal diseases are shown in Tables I and II and in Figure 2. They are quite different in each disease.
T A B L E I

RESULTS OF MEDIASTINOSCOPY IN VARIOUS DISEASES

\begin{tabular}{|c|c|c|c|c|c|c|c|}
\hline \multirow[t]{2}{*}{ Initial Diagnosis } & \multirow[t]{2}{*}{ No. } & \multicolumn{2}{|c|}{$\begin{array}{l}\text { Diagnosis } \\
\text { Confirmed }\end{array}$} & \multicolumn{2}{|c|}{$\begin{array}{c}\text { Different } \\
\text { Diagnosis } \\
\text { Established }\end{array}$} & \multicolumn{2}{|c|}{$\begin{array}{c}\text { False } \\
\text { Negative } \\
\text { Result }\end{array}$} \\
\hline & & No. & $\%$ & No. & $\%$ & No. & $\%$ \\
\hline $\begin{array}{l}\text { Sarcoidosis } \\
\text { Malignant lympho- }\end{array}$ & 125 & 110 & $88 \cdot 0$ & 12 & $9 \cdot 6$ & 3 & $2 \cdot 4$ \\
\hline $\begin{array}{l}\text { granulomatosis } \\
\text { Mediastinal tumours } \\
\text { Tuberculosis } \\
\text { Miscellaneous }\end{array}$ & $\begin{array}{l}60 \\
32 \\
18 \\
35\end{array}$ & $\begin{array}{r}30 \\
5 \\
10 \\
30\end{array}$ & $\begin{array}{l}50 \cdot 0 \\
15.6 \\
55.6 \\
85.7\end{array}$ & $\begin{array}{r}30 \\
13 \\
7 \\
2\end{array}$ & $\begin{array}{r}50 \cdot 0 \\
40 \cdot 6 \\
39 \cdot 9 \\
5 \cdot 7\end{array}$ & $\begin{array}{r}14 \\
1 \\
3\end{array}$ & $\begin{array}{r}43 \cdot 8 \\
5 \cdot 6 \\
8 \cdot 6\end{array}$ \\
\hline Total & 270 & 185 & $68 \cdot 5$ & 64 & $23 \cdot 7$ & 21 & $7 \cdot 8$ \\
\hline
\end{tabular}

T A B L E I I

RESULTS OF MEDIASTINOSCOPY IN LUNG CANCER

\begin{tabular}{c|cc|cc|cc}
\hline $\begin{array}{c}\text { Total } \\
\text { No. }\end{array}$ & $\begin{array}{c}\text { Diagnosis First } \\
\text { Proved By } \\
\text { Mediastinoscopy }\end{array}$ & $\begin{array}{c}\text { Metastases } \\
\text { Found }\end{array}$ & \multicolumn{2}{|c}{$\begin{array}{c}\text { Metastases Not } \\
\text { Found }\end{array}$} \\
\cline { 2 - 6 } & No. & $\%$ & No. & $\%$ & No. & $\%$ \\
\hline 410 & 52 & $12 \cdot 7$ & 139 & $33 \cdot 9$ & $\begin{array}{l}266 \\
\text { Of these, 238 patients } \\
\text { were operated upon and } \\
\text { in 42(17.6\%) metastases } \\
\text { to lymph nodes were } \\
\text { found during operation }\end{array}$ \\
\hline
\end{tabular}

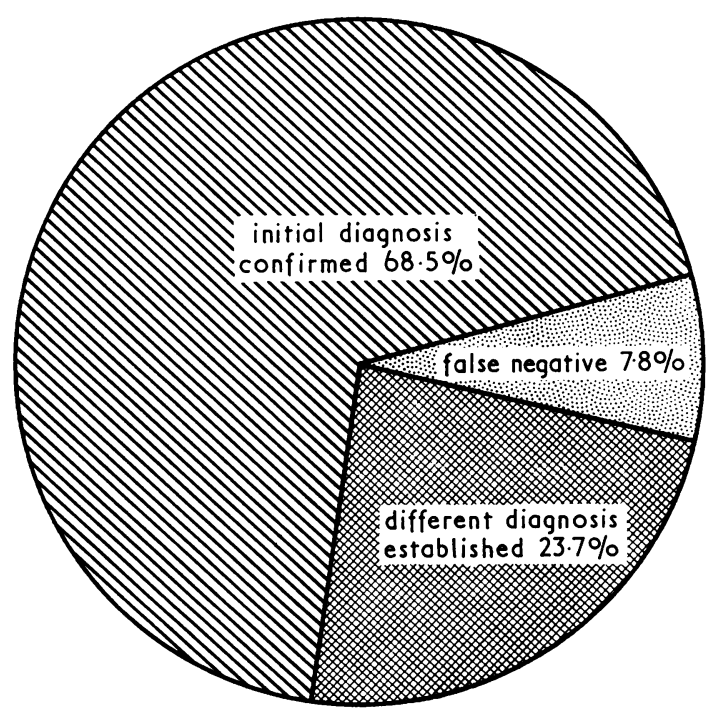

FIG. 2. Summarized results of mediastinoscopy.

Out of 125 mediastinoscopies performed on patients with an initial diagnosis of sarcoidosis, the diagnosis was confirmed histologically in 110 $(88 \%)$. In $12(9.6 \%)$ a different diagnosis was established and in $3(2.4 \%)$ there was a false negative result. This shows the reliability of mediastinoscopy in sarcoidosis. The respective figures 
are even better when the material of the Institute of Tuberculosis, where the greater number of sarcoidosis patients have been investigated, is considered separately (Otto and Piotrowski, 1967 ; Otto, Piotrowski, and Traczyk, 1969). The diagnosis was confirmed in over $95 \%$ of cases. Similar results have been obtained by other authors (Maassen, 1967 ; Ross et al., 1970). Two inferences can be drawn-mediastinoscopy in sarcoidosis is a very reliable method and, because of a decisive correlation between the clinical and histological diagnosis, does not appear to be indicated in all cases of sarcoidosis but should be reserved for doubtful cases. It should be stressed, however, that mediastinoscopy undoubtedly contributed greatly to improving the accuracy of clinical diagnosis. By confirming such a diagnosis it helped to enlarge our clinical experience. It need no longer be considered a routine investigation in sarcoidosis.

Extremely encouraging are the results of mediastinoscopy in patients with an initial diagnosis of Hodgkin's disease. Out of 60 suspected cases mediastinoscopy enabled us to establish another diagnosis in 30 , and in these 30 cases the established diagnosis was correct. It is needless to stress how important it is to exclude positively such a serious disease. Admittedly, in the majority of patients with Hodgkin's disease the correct diagnosis can be assessed by other means, even by biopsy of the peripheral lymph nodes if such are enlarged. However, in this particular disease, an accurate diagnosis can be achieved by mediastinoscopy when other means fail.

The position seems to be reversed in mediastinal tumours. In our material the rate of failure was as high as $43.8 \%$. There are two reasons for this undesirable fact : mediastinal tumours, particularly teratomas, thymomas, and aberrant goitres, are usually surrounded by a thick layer of inflamed mediastinal tissue from which the biopsy is taken and the tumour itself is not reached; and most mediastinal tumours do not give early metastases to the lymphatic system, thus biopsy of the nearest lymph nodes is non-contributory.

Out of the group of patients submitted to mediastinoscopy with an initial diagnosis of mediastinal tumour, in six instances mediastinoscopy saved the patient from thoracotomy-three when Hodgkin's disease was diagnosed and treated conservatively, two when mediastinal cyst was diagnosed and removed by mediastinoscopy, and one case which mediastinoscopy proved inoperable. All the other patients finally required thoracotomy. Mediastinal tumours form only a relative indication for biopsy, because in most cases resection of the tumour is advisable and histology is of lesser importance. In view of this and the high percentage of false negative results, it seems that mediastinoscopy will rarely be employed in mediastinal tumours and thoracotomy remains the procedure of choice as it facilitates both diagnosis and treatment.

The position of mediastinoscopy in establishing the carcinomatous spread of lung cancer, and thus its operability, has often been discussed and its value stressed (Carlens, 1959 ; Sarin and NohlOser, 1969; Hàjek and Homan van der Heide, 1970), particularly in the lower percentage of exploratory thoracotomies. Some studies are in this regard very convincing; however, the final results of the treatment of lung cancer and the number of exploratory thoracotomies in centres where mediastinoscopy is not used do not seem to be inferior (Abbey Smith, 1963). In the presented material 410 patients were mediastinoscoped for lung cancer. In 52 cases mediastinoscopy produced the first successful biopsy and histology of the cancer. Metastases to paratracheal, subcarinal or hilar nodes on the opposite side were found in 139 cases (33.9\%). Out of 266 patients with negative mediastinoscopy findings, 238 were operated upon and in 42 involved lymph nodes were found at operation. This gives the rate of false negative result as $17.6 \%$. This figure is academic, however, as in some cases metastases were found only in the hilar nodes and the lesions were clearly resectable. The percentage of exploratory thoracotomies following the introduction of mediastinoscopy fell from $22 \%$ to $14 \%$.

In view of these figures mediastinoscopy is recommended as a routine investigation in lung cancer although not without some reservation.

Apart from a significant percentage of false negative results, there remains the question whether one feels absolutely justified in not operating on patients in whom mediastinoscopy showed metastases to subcarinal nodes, and who otherwise are operable.

In many such cases the operation might at least prolong life if not cure the patient. Hence mediastinoscopy cannot be considered as the only investigation on which the decision regarding operability is based. Its relative value depends to some extent on the level and accuracy of other investigations, such as pneumoangiography and interpretation of tomograms. It appears that mediastinoscopy could be a great help in centres where, despite all other diagnostic means, the rate of exploratory thoracotomies remains very high. In such centres mediastinoscopy might improve the resectability rate. 
The use of mediastinoscopy in qualifying patients for thoracotomy undoubtedly depends very much on the temperament of the surgeon who operates. For one who observes biological considerations strictly, mediastinoscopy will supply the necessary argument for disqualifying the patient or alternatively increase his conviction that the operation is going to be successful. The more aggressive surgeon, however, will probably find rejection disagreeable in cases which in all other respects are resectable.

In our cases we relied upon mediastinoscopy when it showed metastases to lymph nodes on the opposite side, or into the upper paratracheal nodes above the level of the left innominate vein. We were more liberal when dealing with metastases to the subcarinal nodes, or in the case of right-sided lesions with involvement of the lower paratracheal nodes, if the upper ones were free; some such patients were successfully operated upon with good long-term results.

In a few of our patients mediastinoscopy proved cancer when other histological proof was lacking, but statistically mediastinoscopy is in this respect inferior to both bronchoscopy and direct needle biopsy of the tumour.

In one of our centres mediastinoscopy has also been used to establish the carcinomatous spread of oesophageal cancer. Of 11 patients investigated, in six metastases were found in subcarinal and/or paratracheal nodes. Four of these patients were disqualified from operation and of the two operated upon, one resection was technically possible despite the metastases ; the other was clearly nonresectable. In four out of five patients with negative findings radical operation was carried out; one proved inoperable owing to gross local infiltration by the tumour. No metastases to lymph nodes were found in any of those five patients.

On the basis of this limited experience, it seems advisable to carry out classical mediastinoscopy in cases of oesophageal cancer where there is even the slightest radiological suspicion of mediastinal lymph node enlargement. When metastases to subcarinal or paratracheal nodes are proved, benefit from surgery cannot be expected. On the other hand, it does not seem justifiable to perform in cases of oesophageal cancer an enlarged mediastinoscopy, as advocated by Akovbiantz, Aeberhard, and Linder (1965), because involvement of the lower para-oesophageal nodes cannot always be considered a contra-indication to resection, as such metastases do not exclude long survival. Also the advancing of the mediastinoscope to the lower oesophageal region is a far more difficult procedure than classical mediastinoscopy, and iatrogenic damage is more likely.

The use of an enlarged mediastinoscopy (Specht, 1965) may be indicated when other means of diagnosing lesions of the posterior or anterior mediastinum fail. Despite the limited value of mediastinoscopy in obtaining a positive biopsy of mediastinal tumours, on three occasions we achieved such a biopsy of neurogenic tumours in the posterior mediastinum, which enabled diagnosis and treatment.

In lesions localized low in the anterior mediastinum it may sometimes be convenient to perform the mediastinoscopy from below the sternum. We achieved positive biopsies in two benign lesions using this technique.

Finally, mediastinoscopy may be of some value in assessing operability in patients with the Pancoast syndrome. We used it in two such cases, and as there were no involved lymph nodes, resections including the involved ribs were carried out with satisfactory results.

On the basis of our experience, mediastinoscopy can be considered as a safe method and the number of occurring complications low (Table III). In 11

T A B L E I I I

COMPLICATIONS OF MEDIASTINOSCOPY

\begin{tabular}{|c|c|c|c|}
\hline Complication & No. & Treatment & Final Result \\
\hline Haemorrhage & 11 & Temporary & Full recovery \\
\hline $\begin{array}{l}\text { Damage to } \\
\text { recurrent nerve } \\
\text { Pneumothorax } \\
\text { Wound suppuration }\end{array}$ & $\begin{array}{r}3 \\
1 \\
13\end{array}$ & $\begin{array}{l}\text { None } \\
\text { Pleural suction } \\
\text { Drainage of the } \\
\text { wound }\end{array}$ & $\begin{array}{l}\text { Partial paralysis } \\
\text { of vocal cord } \\
\text { Full recovery } \\
\text { Full recovery }\end{array}$ \\
\hline
\end{tabular}

patients bleeding was observed during mediastinoscopy; this was, however, controlled in all cases by applying a fibrin sponge and coagulation without the necessity of thoracotomy and with a satisfactory outcome. Suppuration of the wound took place in 13 patients; in all it was limited to skin, or to skin and subcutaneous tissue only, and cleared up within a few days. In one case the pleura was accidentally opened, which required pleural suction, and the patient recovered fully. In three cases, during dissection of the hilar nodes iatrogenic damage to the recurrent laryngeal nerve was produced, resulting in some hoarseness of voice. No other complications were observed.

In summary, it can be said that mediastinoscopy is a reliable method in mediastinal and pulmonary diseases involving the lymphatic system. Its value in mediastinal tumours is limited. In selected cases 
of pulmonary and oesophageal cancer it allows establishment of operability, thus diminishing the percentage of exploratory thoracotomies.

\section{REFERENCES}

Abbey Smith, R. (1963). Surgery in the treatment of locally advanced lung carcinoma. Thorax, 18, 21.

Akovbiantz, A., Aeberhard, P., and Linder E. (1965). Die Mediastinoskopie in der Operabilitätsbeurteilung bei Oesophaguskarzinom. Schweitz. med. Wschr., 95, 168.

Carlens, E. (1959). Mediastinoscopy: A method for inspection and tissue biopsy in the superior mediastinum. Dis. Chest, 36, 343.

- Johansson, L., Karlöf, I., and Lagergren, H. (1965). New method for atrial-triggered pacemaker treatment without thoracotomy. J. thorac. cardiovasc. Surg., 50, 229.

- and Olsson, P. (1967). La mediastinoscopie auxiliaire de la thymectomie par voie cervicale. Bronches, 17, 408.

Hàjek, M., and Homan van der Heide, J. N. (1970). Early detection of mediastinal spread of pulmonary carcinoma by mediastinoscopy. Thorax, 25, 720 .
Maassen, W. (1967). Ergebnisse und Bedeutung der Mediastinoskopie. Springer, Berlin.

Otto, T. J., and Piotrowski, M. (1967). La mediastinoscopie dans le diagnostic des affections médiastino-pulmonaires avec référence à la sarcoidose. Bronches, 17, 413.

- - and Traczyk, K. (1969). Assessment of the value of mediastinoscopy in mediastinal and pulmonary diseases on the basis of 100 own cases. Pol. med. J., $8,608$.

Ross, J. K., Mikhail, J. R., Drury, R. A. B., Levis, R. D., and Mitchell, D. N. (1970). Mediastinoscopy. Thorax, 25, 312.

Sarin, C. L., and Nohl-Oser, H. C. (1969). Mediastinoscopy: a clinical evaluation of 400 consecutive cases. Thorax, $24,585$.

Specht, G. (1965). Erweiterte Mediastinoskopie. Thoraxchir. vascul. Chir., 13, 401.

Stopczyk, M., Sitkowski, W., Otto, T. J., Pieniak, M., Askanas, A., Kraska, T., and Sadowski, Z. (1968). Stymulatory sterowane rytmem przedsionkow $w$ leczeniu bloku przedsionkowo-komorowego. Pol. Arch. Med. Wewnet., 41, 783.

Zenker, R. (1965). Allgemeine und spezielle chirurgische Operationslehre, vol.6, p. 482. 